\title{
Left Ventricular Mid Inferolateral Segment
}

National Cancer Institute

\section{Source}

National Cancer Institute. Left Ventricular Mid Inferolateral Segment. NCI Thesaurus.

Code C127665.

The inferolateral portion of the mid-cavity division of the left ventricular myocardium as determined using the AHA 17-Segment Model (Cerqueira et al., 2002). 